\title{
Association Between Early Central Venous Pressure Measurement and Mortality in Patients With Sepsis: A Retrospective Study
}

Han Chen

Fujian Provincial Hospital

Shu-Rong Gong

Fujian Provincial Hospital

Xiu-Ling Shang

Fujian Provincial Hospital

Rong-Guo Yu ( $\sim$ garyyrg@126.com )

Fujian Provincial Hospital

\section{Research}

Keywords: Central venous pressure, sepsis, fluid resuscitation, MIMIC-III, mortality

Posted Date: July 29th, 2020

DOI: https://doi.org/10.21203/rs.3.rs-48919/v1

License: (c) (i) This work is licensed under a Creative Commons Attribution 4.0 International License. Read Full License 


\section{Abstract}

Background: It remains controversial to abandon central venous pressure (CVP) in the monitoring of fluid resuscitation in sepsis patients. We hypothesized that early CVP measurement was associated with decreased mortality in critically ill patients with sepsis.

Methods: Critically ill patients with sepsis were identified from the Medical Information Mart for Intensive Care (MIMIC)-III database. Patients were divided into two groups base on whether or not they had a CVP measurement within the first 6 hours of ICU stay. The primary endpoint was 28-day mortality. Patients were further divided into four subgroups base on the time when the first CVP measurement was obtained: within 3 hours, between 3 and 6 hours, between 6 and 12 hours, and not measured within 12 hours. Kaplan-Meier survival analysis and Cox regression model were used for univariate and multivariate analyses of survival, respectively.

RESULTS: A total of 4733 sepsis patients were included. The 28-day mortality was significantly lower in the CVP measured group than in the control group (34.2 vs. 40.7, $p<0.001)$. A "U"-shaped relationship between initial CVP and mortality was identified. With patients without CVP measured within 12 hours serving as the reference subgroup, timely CVP measurement was associated with decreased 28-day mortality before and after adjusting for confounding variables.

CONCLUSIONS: Early CVP measurement is associated with decreased 28-day mortality in patients with sepsis. CVP should be considered as a valuable and easily accessible safety parameter during (early) fluid resuscitation.

\section{Background}

Sepsis and septic shock remain the main causes of admission to the intensive care unit (ICU) and death in critically ill patients [1]. During this first phase of treatment ("the salvage phase" [2]), one of the main therapies is fluid administration to restore blood pressure and cardiac output. Previous Surviving Sepsis Campaign (SSC) guidelines have recommended administering fluid to target central venous pressure (CVP) level [3], yet it is no longer recommended by the latest updated SSC guidelines [4]. It remains controversial to abandon CVP in the monitoring of fluid resuscitation in sepsis patients $[5,6]$. CVP is often misinterpreted as an indicator of intravascular volume status. From the (patho)physiological point of view, CVP is determined by the interaction of cardiac function and venous return function, as suggested by Guyton et al. [7], and therefore does not merely reflect the intravascular volume status. Small changes in CVP along with increases in cardiac output (CO) indicate fluid responsiveness, which would thus lead to fluid administration in sepsis patients with evidence of tissue hypoperfusion. In contrast, significant increases in CVP with little changes in CO suggest poor tolerance to fluids, in which case patients are at high risk of fluid overload and may benefit little from fluids.

It is true that using CVP values to guide fluid resuscitation is far from perfect. However, CVP provides a useful indication of how well the heart interacts with venous return. To a given high CVP value, it could 
attribute to either cardiac dysfunction or fluid overload, or both, if intra-thoracic hypertension caused by other factors is excluded. CVP can thus serve as a safety variable for when to stop or not to give additional fluids. This is important since sepsis patients admitted to ICU is very likely to receive a large amount of fluid before ICU admission. Low CVP, on the other hand, can be helpful for detecting inadequate fluid resuscitation but should be used with caution and together with additional monitoring. We hypothesized that early CVP measurement in the ICU was associated with decreased mortality in critically ill patients with sepsis. Data of patients with sepsis were retrospectively collected, and the association between early CVP measurement and mortality was explored.

\section{Methods}

\section{Database}

The data of the present study were collected from the Multiparameter Intelligent Monitoring in Intensive Care Database III (MIMIC III) [8]. In brief, MIMIC-III database is maintained by the Laboratory for Computational Physiology at the Massachusetts Institute of Technology. It contains de-identified healthrelated data associated with over forty thousand patients who stayed in critical care units of the Beth Israel Deaconess Medical Center between 2001 and 2012. The institutional review boards of the Massachusetts Institute of Technology (Cambridge, MA) and Beth Israel Deaconess Medical Center (Boston, MA) approved the establishment of the database. Therefore, consent was obtained for the original data collection and waived for the present study. Data were extracted by Dr. Shu-Rong Gong and Dr. Han Chen, who completed the online training course of the National Institutes of Health (certification number: SRG 35606844, HC 36014736).

\section{Data extraction}

PostgreSQL tools V.1.09 was used for data extraction. The following data were extracted by using Structured Query Language (SQL): age, gender, co-morbidities, the survival time, length of hospital stay, and length of ICU stay, sequential organ failure assessment (SOFA) score, vital signs, first-day lab results, use of vasopressors, daily fluid input, fluid balance, urine output, need for renal replacement therapy and mechanical ventilation, the present of sepsis, and the initial time and value of the first CVP measurement in the ICU.

\section{Population and endpoint}

All patients with sepsis were included. Patients younger than 18 years old were excluded. Patients were divided into two groups base on whether or not they had a CVP measurement within the first 6 hours of ICU stay (i.e., the CVP measured group and the control group). The primary endpoint was 28-day mortality.

\section{Statistical analysis}


Continuous variables were presented as mean with standard deviation or median with interquartile ranges. Student's $t$-test or Wilcoxon rank-sum test were used as appropriate. Categorical variables were presented as counts (percentages) and compared using the chi-square test. We used a locally weighted smoothing (Lowess Smoothing) technique to explore the crude relationship between initial CVP values and mortality. Patients were further divided into four subgroups base on the time when the first CVP measurement was obtained: within 3 hours, between 3 and 6 hours, between 6 and 12 hours, and not measured within 12 hours, and the Kaplan-Meier survival analysis was performed as a univariate analysis of survival, tested by the Log-Rank test. Cox regression model was used to estimate the relationships of the timeliness of CVP measurement and mortality adjusting for confounding variables (with a $p$-value $<0.05$ in univariate analysis or potential confounders judged by clinical expertise).

\section{Results}

A total of 4733 sepsis patients were included, where 1673 patients had a CVP measurement within the first 6 hours of ICU stay, and another 3060 patients were allocated into the control group. Baseline patient characteristics are summarized in Table 1. It is worth mentioning that patients in the CVP measured group had higher initial lactate acid level, higher SOFA score, but a lower rate of underlying renal failure (Table 1). 
Table 1

Baseline patient characteristics

\begin{tabular}{|c|c|c|c|}
\hline & $\begin{array}{l}\text { CVP not measured } \\
\text { within } 6 \mathrm{hr} \\
(\mathrm{n}=3060)\end{array}$ & $\begin{array}{l}\text { CVP measured within } \\
6 \mathrm{hr} \\
(n=1673)\end{array}$ & $\begin{array}{l}p- \\
\text { value }\end{array}$ \\
\hline Male (\%) & $1372(44.8)$ & 714 (42.7) & 0.153 \\
\hline Age (yr) & $66.9 \pm 15.9$ & $67.6 \pm 15.5$ & 0.123 \\
\hline Obesity (\%) & $190(6.2)$ & $111(6.6)$ & 0.566 \\
\hline \multicolumn{4}{|l|}{ Co-morbidities } \\
\hline Congestive heart failure (\%) & $1080(35.3)$ & $594(35.5)$ & 0.885 \\
\hline Cardiac arrhythmia (\%) & $1065(34.8)$ & $563(33.7)$ & 0.425 \\
\hline Valvular disease (\%) & $302(9.9)$ & $160(9.6)$ & 0.735 \\
\hline Hypertension (\%) & $575(18.8)$ & $278(16.6)$ & 0.063 \\
\hline Paralysis (\%) & $134(4.4)$ & $63(3.8)$ & 0.312 \\
\hline Chronic pulmonary disease (\%) & $664(21.7)$ & $348(20.8)$ & 0.471 \\
\hline Diabetes mellitus (\%) & $1031(33.7)$ & $570(34.1)$ & 0.793 \\
\hline Renal failure (\%) & 787 (25.72) & $350(20.92)$ & $\begin{array}{l}< \\
0.001\end{array}$ \\
\hline Liver disease (\%) & $401(13.1)$ & $203(12.1)$ & 0.339 \\
\hline Tumor (\%) & $397(13.0)$ & $231(13.8)$ & 0.419 \\
\hline \multicolumn{4}{|l|}{ Admission status } \\
\hline SOFA score & $6.8 \pm 3.8$ & $8.2 \pm 3.8$ & $<.001$ \\
\hline Initial lactate (mmol/L) & $1.9(1.3,3.3)$ & $2.3(1.4,3.7)$ & $<.001$ \\
\hline $\begin{array}{l}\text { Max white blood cell count within } 24 \\
\text { hr (K/uL) }\end{array}$ & $14.4(9.5,20.9)$ & $15.9(10.7,23.4)$ & $<.001$ \\
\hline Min hemoglobin within $24 \mathrm{hr}(\mathrm{g} / \mathrm{dL})$ & $9.3(8.1,10.7)$ & $9.3(8.2,10.5)$ & 0.889 \\
\hline Min platelet within $24 \mathrm{hr}(\mathrm{K} / \mathrm{uL})$ & $178(104,275)$ & $171(104,250)$ & 0.03 \\
\hline
\end{tabular}

Data are presented as mean \pm standard deviation or median (interquartile range) for continuous variables, and counts (percentages) for categorical variables.

CVP central venous pressure, SOFA sequential organ failure assessment 


\begin{tabular}{|llll|}
\hline & $\begin{array}{l}\text { CVP not measured } \\
\text { within } 6 \mathrm{hr} \\
(\mathbf{n = 3 0 6 0})\end{array}$ & $\begin{array}{l}\text { CVP measured within } \\
\mathbf{6} \mathrm{hr} \\
(\mathbf{n}=1673)\end{array}$ & $\begin{array}{c}p \text { - } \\
\text { value }\end{array}$ \\
\hline Min albumin within $24 \mathrm{hr}(\mathrm{g} / \mathrm{dL})$ & $2.7(2.3,3.1)$ & $2.6(2.2,3.0)$ & 0.001 \\
\hline Max creatine within $24 \mathrm{hr}(\mathrm{mg} / \mathrm{dL})$ & $2.2 \pm 1.9$ & $2.2 \pm 1.8$ & 0.544 \\
\hline $\begin{array}{l}\text { Max blood glucose within } 24 \mathrm{hr} \\
(\mathrm{mg} / \mathrm{dL})\end{array}$ & $152(120,205)$ & $167(132,219)$ & 0.001 \\
\hline $\begin{array}{l}\text { Data are presented as mean } \pm \text { standard deviation or median (interquartile range) for continuous } \\
\text { variables, and counts (percentages) for categorical variables. }\end{array}$ \\
\hline \multicolumn{2}{l|l}{ CVP central venous pressure, SOFA sequential organ failure assessment } \\
\hline
\end{tabular}

The 28-day mortality was significantly lower in the CVP measured group than in the control group (34.2 vs. 40.7, $p<0.001$, Table 2). Compare to the control group, the hospital length of stay was significantly shorter in the CVP measured group, but the ICU length of stay was significantly longer. More patients needed mechanical ventilation in the CVP measured group, but there was no difference in the duration of mechanical ventilation. Similarly, more patients needed vasopressors in the CVP measured group, but no difference in the duration of vasopressor use was observed. No difference in the occurrence of acute kidney injury (AKI), need for renal replacement therapy, or urine output was observed (Table 2). 
Table 2

Unadjusted outcomes in patients with or without CVP measured within 6 hours

\begin{tabular}{|c|c|c|c|}
\hline & $\begin{array}{l}\text { CVP not measured within } \\
6 \mathrm{hr} \\
(\mathrm{n}=3060)\end{array}$ & $\begin{array}{l}\text { CVP measured within } 6 \\
\mathrm{hr} \\
(\mathrm{n}=1673)\end{array}$ & $\begin{array}{l}p- \\
\text { value }\end{array}$ \\
\hline 28-day mortality (\%) & $1246(40.7)$ & $572(34.2)$ & $<0.001$ \\
\hline Length of ICU stay (day) & $4.0(1.9,9.5)$ & $4.6(2.2,10.4)$ & $<0.001$ \\
\hline Length of hospital stay (day) & $12.4(6.0,24.6)$ & $11.5(6.0,22.4)$ & 0.019 \\
\hline $\begin{array}{l}\text { Occurrence of acute renal injury } \\
(\%)\end{array}$ & 2469 (80.69) & $1384(82.73)$ & 0.085 \\
\hline $\begin{array}{l}\text { Need for mechanical ventilation } \\
(\%)\end{array}$ & $1671(54.61)$ & 1119 (66.89) & $<.001$ \\
\hline $\begin{array}{l}\text { Need for renal replacement } \\
\text { therapy (\%) }\end{array}$ & $292(9.5)$ & $180(10.8)$ & 0.182 \\
\hline Need for vasopressors (\%) & $1810(59.2)$ & $1403(83.9)$ & $<0.001$ \\
\hline $\begin{array}{l}\text { Mechanical ventilation duration } \\
\text { (hour) }\end{array}$ & $118(37,260)$ & $110(38,250)$ & 0.389 \\
\hline Vasopressor duration (hour) & $31(12,68)$ & $31(13,63)$ & 0.513 \\
\hline Urine output on day 1 (mL) & $1188(590,2010)$ & $1168(560,2110)$ & 0.912 \\
\hline \multicolumn{4}{|c|}{$\begin{array}{l}\text { Data are presented as median (interquartile range) for continuous variables, and counts (percentages) } \\
\text { for categorical variables. }\end{array}$} \\
\hline$C V P$ central venous pressure, $I C$ & ive care unit & & \\
\hline
\end{tabular}

A "U"-shaped relationship between initial CVP and mortality was found (Fig. 2). The 28-day survival was significantly different among patients with CVP measured at different time points (Fig. 3). Compare to patients without CVP measured within 12 hours, patients with CVP measured within 3 hours had significantly lower mortality, but no significant difference was observed in the other subgroups (adjusted $p<0.001,=0.053$, and $>0.999$, respectively; Fig. 3 ).

With patients without CVP measured within 12 hours serving as the reference group, timely CVP measurement was associated with decreased 28-day mortality before adjusting for confounding variables. After adjusting age, gender, SOFA score, initial lactate, renal failure, and the first-day lab results, including max blood glucose, minimum platelet and max white blood cell count, the association between timely CVP measurement and decreased 28-day mortality was still observed (Table 3). 
Table 3

Adjusted hazard ratio using timepoint of CVP measurement as the design variable

\section{Unadjusted outcomes by CVP measurement categories}

\begin{tabular}{|llll|}
\hline Variable & HR & $\begin{array}{l}95 \% \\
\text { Cl }\end{array}$ & $\begin{array}{l}p \text { - } \\
\text { value }\end{array}$ \\
$\begin{array}{l}\text { CVP measured } \\
\text { within 3 hr }\end{array}$ & 0.79 & $\begin{array}{l}(0.70, \\
0.89)\end{array}$ & 0.001 \\
\hline $\begin{array}{l}\text { CVP measured } \\
\text { between 3 and 6 hr }\end{array}$ & 0.84 & $\begin{array}{l}(0.73, \\
0.97)\end{array}$ & 0.021 \\
$\begin{array}{l}\text { CVP measured } \\
\text { between 6 and 12 } \\
\text { hr }\end{array}$ & 0.98 & $\begin{array}{l}(0.84, \\
1.14)\end{array}$ & 0.757 \\
$\begin{array}{l}\text { CVP not measured } \\
\text { within 12 hr }\end{array}$ & Ref. & & \\
\hline
\end{tabular}

Adjusted outcomes with confounding variables included in the model

\begin{tabular}{|c|c|c|c|}
\hline Variable & $\mathrm{HR}$ & $\begin{array}{l}95 \% \\
\mathrm{Cl}\end{array}$ & $\begin{array}{l}p- \\
\text { value }\end{array}$ \\
\hline $\begin{array}{l}\text { CVP measured within } \\
3 \mathrm{hr}\end{array}$ & 0.65 & $\begin{array}{l}(0.55, \\
0.77)\end{array}$ & $\dot{c}_{0.001}$ \\
\hline $\begin{array}{l}\text { CVP measured } \\
\text { between } 3 \text { and } 6 \mathrm{hr}\end{array}$ & 0.72 & $\begin{array}{l}(0.6 \\
0.87)\end{array}$ & 0.001 \\
\hline $\begin{array}{l}\text { CVP measured } \\
\text { between } 6 \text { and } 12 \mathrm{hr}\end{array}$ & 0.8 & $\begin{array}{l}(0.66, \\
0.98)\end{array}$ & 0.032 \\
\hline $\begin{array}{l}\text { CVP not measured } \\
\text { within } 12 \mathrm{hr}\end{array}$ & Ref. & & \\
\hline Gender & 1.02 & $\begin{array}{l}(0.89 \\
1.16)\end{array}$ & 0.820 \\
\hline Age & 1.02 & $\begin{array}{l}(1.01 \\
1.02)\end{array}$ & $\begin{array}{l}< \\
0.001\end{array}$ \\
\hline SOFA & 1.13 & $\begin{array}{l}(1.1 \\
1.15)\end{array}$ & $\dot{0} 001$ \\
\hline Initial lactate & 1.12 & $\begin{array}{l}(1.1 \\
1.14)\end{array}$ & $\dot{0} 001$ \\
\hline $\begin{array}{l}\text { Max blood glucose } \\
\text { within } 24 \mathrm{hr}\end{array}$ & 1 & $(1,1)$ & 0.139 \\
\hline $\begin{array}{l}\text { Min platelet within } \\
24 \mathrm{hr}\end{array}$ & 1 & $(1,1)$ & 0.770 \\
\hline $\begin{array}{l}\text { Max WBC within } 24 \\
\text { hr }\end{array}$ & 1 & $(1,1)$ & 0.900 \\
\hline Renal failure & 0.94 & $\begin{array}{l}(0.81, \\
1.09)\end{array}$ & 0.419 \\
\hline
\end{tabular}

Patients were divided into four subgroups base on the time when the first CVP measurement was obtained: within 3 hours, between 3 and 6 hours, between 6 and 12 hours, and not measured within 12 hours. Two COX proportional hazards models were built with the CVP not measured within 12 hours subgroup as the reference group.

$C V P$ central venous pressure, $C /$ confidence interval, $H R$ hazard ratio, SOFA sequential organ failure assessment, $W B C$ white blood cell count

\section{Discussion}


The main findings of the present study were: 1) the 28-day mortality was significantly lower in patients with CVP measured within 6 hours than in those who did not; 2) the improvement of 28-day mortality was associated with the time when the CVP measurement was established.

The results of three recent multi-center randomized controlled trials (ProCESS, ARISE and ProMISe) have led to the abandonment of the "early goal-directed therapy" (EGDT) strategy $[9,10]$. CVP is no longer recommended to guide fluid resuscitation by the most recent SSC guidelines [4]. Instead, dynamic measures of assessing fluid responsiveness, encompass passive leg raises, fluid challenges against stroke volume measurements, or the variations in systolic pressure, pulse pressure, or stroke volume to changes in intrathoracic pressure induced by mechanical ventilation, are recommended. However, new concerns regarding the concept of fluid responsiveness have been raised: "volume responsive, but does the patient need volume?" [11]

What is the significance of CVP measurement in this context? CVP is determined by the complex interplay of the preload, afterload, compliance, and contractility of the right ventricle, venous tone, volume status, abdominal and intrathoracic pressure, and many other factors [12]. For simplicity, it can be interpreted as that measured CVP is determined by the interaction of the cardiac and venous return functions [13]. Indeed, a single static measurement of CVP does not predict blood volume or fluid responsiveness. However, this statement misses the value of CVP as a readily available indicator that mirrors the complex interaction between the heart and the blood returning from circulation. In other words, CVP is more likely a "dependent variable" in this interplay rather than an "independent variable." The "independent variables," on the other hand, are intravascular volume and cardiac function, which are manipulated in daily clinical practice (for instance, fluid administration for intravascular volume and inotropic agents for cardiac function). In this point of view, CVP does not indicate volume status, and in isolation, it is not a strong predictor of fluid responsiveness. But an abnormal CVP value must attribute to either abnormal intravascular volume or abnormal cardiac function, or both, and the choice of further (advanced) assessments can be made by the measurement of CVP (e.g., echocardiography, inferior vena cava diameter, CO measurement via thermal dilution, etc.). Together with the further evaluations, the decision whether to continue or stop fluid administration or even to achieve a negative fluid balance (i.e., "reverse fluid resuscitation"), can be made.

In the present study, our data suggested a " $U$ " shape relationship between initial CVP and 28-day mortality. As discussed above, an extremely low CVP value may due to hypovolemia or a hyperdynamic heart in the setting of sepsis. Patients are at higher risk of mortality if hypovolemia is inadequately resuscitated [4]. The association between elevated CVP and increased mortality has been found by numerous studies [14-19]. Besides, since CVP serves as the backpressure of venous return, upstream capillary pressures must be even higher in the setting of increased CVP to maintain an intact venous return. Therefore, clinicians should not only further look into cardiac function or intravascular volume, but also the possible impact of venous congestion on upstream organs. The association between elevated CVP and kidney dysfunction has also been found in critically ill patients [18,20,21]. In the perspective of venous return function, under the premise of maintaining adequate tissue perfusion, CVP should be 
maintained as low as possible to allow an adequate venous return, and thus to increase CO (in a steady condition, $\mathrm{CO}$ must equal venous return) and reduce tissue edema.

Criticisms have been raised since the current SSC guidelines recommend intravenous infusing at least $30 \mathrm{~mL} / \mathrm{kg}$ of crystalloids within the first three hours of resuscitation [5]. A fixed, large volume of fluid infusion could result in fluid overload. As previously discussed, a high CVP indicates either fluid overload or the current cardiac function is incapable of matching the increased venous return. Either way, the fluid infusion should be discontinued. Early CVP monitoring may be helpful in reducing the risk of fluid overload. In this setting, CVP can serve as a safe limit rather than a target of fluid resuscitation [22]. Our data suggested that early CVP measurement was associated with decreased 28-day mortality, which can be partially explained in this way.

Higher baseline SOFA score and initial lactate were observed in patients who received CVP measurement within 6 hours, suggested a more severe illness of the patients. Interestingly, these sicker patients had better survival than the controls. After adjusting the confounding variables in multivariate analysis, we found that early CVP measurement was the independent factor associated with decreased mortality. However, it should be emphasized that it is not the monitoring, but the adjustment of interventions given by the caregivers based on the results of the monitoring improves patients' outcomes. Although a causeeffect relationship cannot be established in this retrospective study, given the nature of cheap, easily obtainable, and repeatable, early CVP measurement is still a valuable aid for diagnosis and hemodynamic management when properly understood, especially in preventing fluid over-resuscitation.

This study has several limitations. First, the study was limited by the nature of retrospective design and the source of data used. For this reason, no cause-effect relationships could be established. Second, although some confounding variables were adjusted in multivariate analysis, confirming that early CVP measurement was associated with poor outcomes, the results may be affected by other confounding variables related to organ damage or mortality. Additional prospective studies are needed to investigate the association between CVP monitoring and treatment adjustments and the related outcomes to these adjustments.

\section{Conclusions}

Early CVP measurement is associated with decreased 28-day mortality in patients with sepsis. CVP should be considered as a valuable and easily accessible safety parameter during (early) fluid resuscitation.

\section{Abbreviations}

AKI

acute kidney injury; $\mathrm{CO}$ = cardiac output; $\mathrm{CVP}=$ central venous pressure; $\mathrm{EGDT}$ = early goal-directed therapy; HR = hazard ratio; ICU = intensive care unit; MIMIC = Medical Information Mart for Intensive Care; 
SOFA = sequential organ failure assessment; $\mathrm{SQL}=$ Structured Query Language; $S S C$ = Surviving Sepsis Campaign; WBC $=$ white blood cell count

\section{Declarations}

\section{Ethics approval and consent to participate}

The institutional review boards of the Massachusetts Institute of Technology (Cambridge, MA) and Beth Israel Deaconess Medical Center (Boston, MA) approved the establishment of the database. Therefore, consent was obtained for the original data collection and waived for the present study.

\section{Consent for publication}

Not applicable

\section{Availability of data and material}

The datasets used and analyzed during the present study are available from the corresponding author on reasonable request.

\section{Competing interests}

The authors declare that they have no competing interests

\section{Funding:}

$\mathrm{HC}$ is supported by the National Natural Science Foundation of China (Grant No. 81701942) and the High-level Hospital Foster Grants from Fujian Provincial Hospital (Grant Number: 2020HSJJ02). RongGuo Yu is supported by the High-level hospital grants from Fujian Provincial Hospital (Grant number: (2017)510\#).

\section{Author Contributions:}

Conception and design: HC, XLS, RGY; Data collection and analysis. HC, SRG; Drafting the manuscript. $\mathrm{HC}, \mathrm{SRG}, \mathrm{SLS}, \mathrm{RGY}$. All authors have read and approved the manuscript.

\section{Acknowledgments}

None 


\section{References}

1. Singer M, Deutschman CS, Seymour CW, Shankar-Hari M, Annane D, Bauer M et al. The Third International Consensus Definitions for Sepsis and Septic Shock (Sepsis-3). JAMA. 2016;315:801-10.

2. Vincent JL, De Backer D. Circulatory shock. N Engl J Med. 2013;369:1726-34.

3. Dellinger RP, Levy MM, Rhodes A, Annane D, Gerlach H, Opal SM et al. Surviving Sepsis Campaign: international guidelines for management of severe sepsis and septic shock, 2012. Intensive Care Med. 2013;39:165-228.

4. Rhodes A, Evans LE, Alhazzani W, Levy MM, Antonelli M, Ferrer R et al. Surviving Sepsis Campaign: International Guidelines for Management of Sepsis and Septic Shock: 2016. Intensive Care Med. 2017;43:304-77.

5. Jozwiak M, Hamzaoui O, Monnet X, Teboul JL. Fluid resuscitation during early sepsis: a need for individualization. Minerva Anestesiol. 2018;84:987-92.

6. Mallat J, Reddi BJ. Do not abandon monitoring the central venous pressure during fluid resuscitation of septic shock patients. Intensive Care Med. 2018;44:2012-3.

7. Guyton AC. Determination of cardiac output by equating venous return curves with cardiac response curves. Physiol Rev. 1955;35:123-9.

8. Johnson AE, Pollard TJ, Shen L, Lehman LW, Feng M, Ghassemi M et al. MIMIC-III, a freely accessible critical care database. Sci Data. 2016;3:160035.

9. Yealy DM, Kellum JA, Huang DT, Barnato AE, Weissfeld LA, Pike $F$ et al. A randomized trial of protocol-based care for early septic shock. N Engl J Med. 2014;370:1683-93.

10. Mouncey PR, Osborn TM, Power GS, Harrison DA, Sadique MZ, Grieve RD et al. Trial of early, goaldirected resuscitation for septic shock. N Engl J Med. 2015;372:1301-11.

11. Takala J. Volume responsive, but does the patient need volume? Intensive Care Med. 2016;42:14613.

12. Gelman S. Venous function and central venous pressure: a physiologic story. Anesthesiology. 2008;108:735-48.

13. Magder S. Right Atrial Pressure in the Critically III: How to Measure, What Is the Value, What Are the Limitations? Chest. 2017;151:908-16.

14. Lobo SM, Rezende E, Knibel MF, Silva NB, Páramo JA, Nácul FE et al. Early determinants of death due to multiple organ failure after noncardiac surgery in high-risk patients. Anesth Analg. 2011;112:87783.

15. Chung KP, Chang HT, Huang YT, Liao CH, Ho CC, Jerng JS et al. Central venous oxygen saturation under non-protocolized resuscitation is not related to survival in severe sepsis or septic shock. Shock. 2012;38:584-91.

16. Li DK, Wang XT, Liu DW. Association between elevated central venous pressure and outcomes in critically ill patients. Ann Intensive Care. 2017;7:83. 
17. Long $\mathrm{Y}$, Su L, Zhang Q, Zhou X, Wang H, Cui $\mathrm{N}$ et al. Elevated Mean Airway Pressure and Central Venous Pressure in the First Day of Mechanical Ventilation Indicated Poor Outcome. Crit Care Med. 2017;45:e485-e92.

18. Chen CY, Zhou Y, Wang P, Qi EY, Gu WJ. Elevated central venous pressure is associated with increased mortality and acute kidney injury in critically ill patients: a meta-analysis. Crit Care. 2020;24:80.

19. Boyd JH, Forbes J, Nakada TA, Walley KR, Russell JA. Fluid resuscitation in septic shock: a positive fluid balance and elevated central venous pressure are associated with increased mortality. Crit Care Med. 2011;39:259-65.

20. Wong BT, Chan MJ, Glassford NJ, Mårtensson J, Bion V, Chai SY et al. Mean arterial pressure and mean perfusion pressure deficit in septic acute kidney injury. J Crit Care. 2015;30:975-81.

21. Legrand M, Dupuis C, Simon C, Gayat E, Mateo J, Lukaszewicz AC et al. Association between systemic hemodynamics and septic acute kidney injury in critically ill patients: a retrospective observational study. Crit Care. 2013;17:R278.

22. Pinsky MR, Kellum JA, Bellomo R. Central venous pressure is a stopping rule, not a target of fluid resuscitation. Crit Care Resusc. 2014;16:245-6.

\section{Figures}




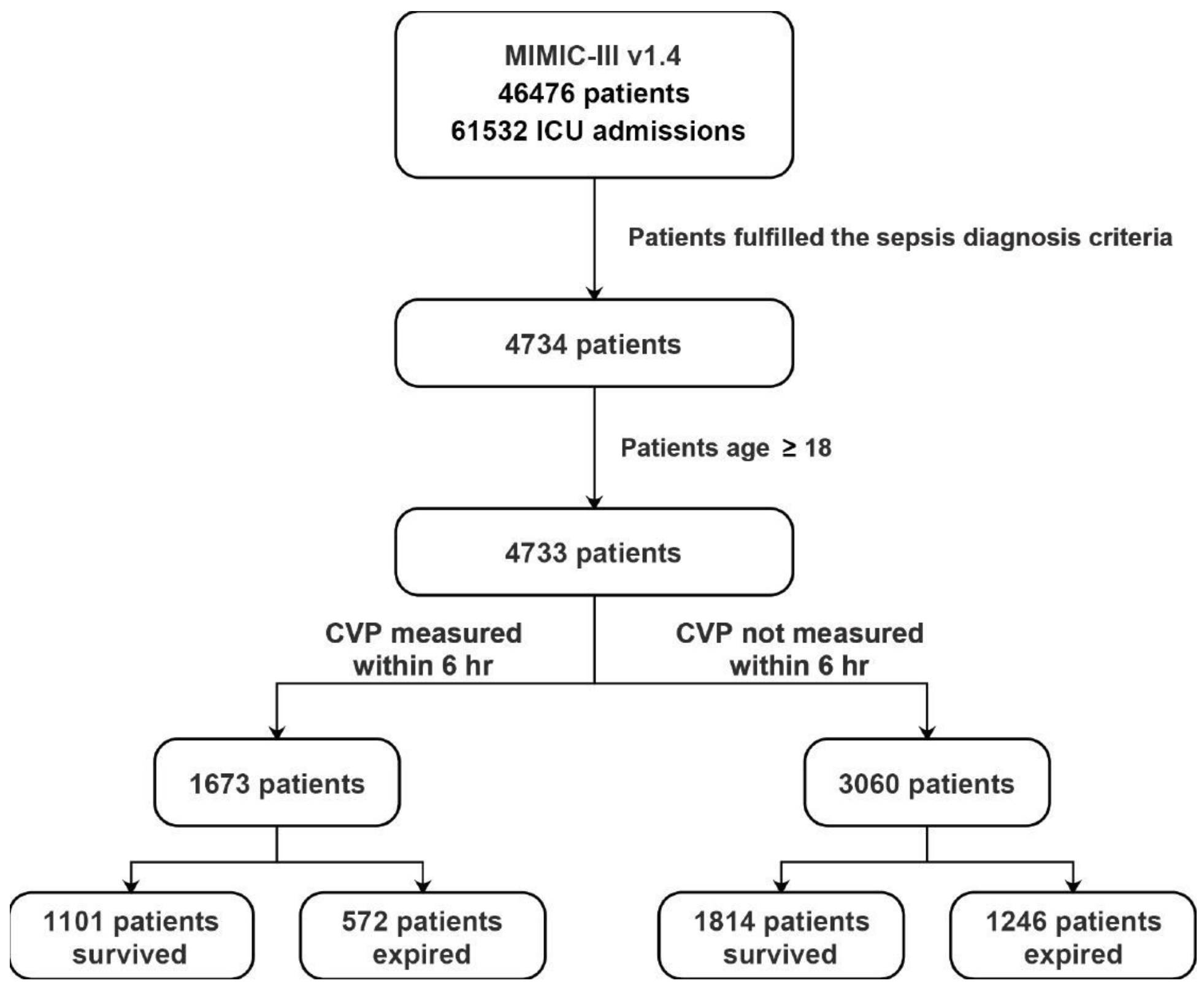

Figure 1

Flowchart showing a step-by-step selection of patients included in the study CVP central venous pressure, ICU intensive care unit. 


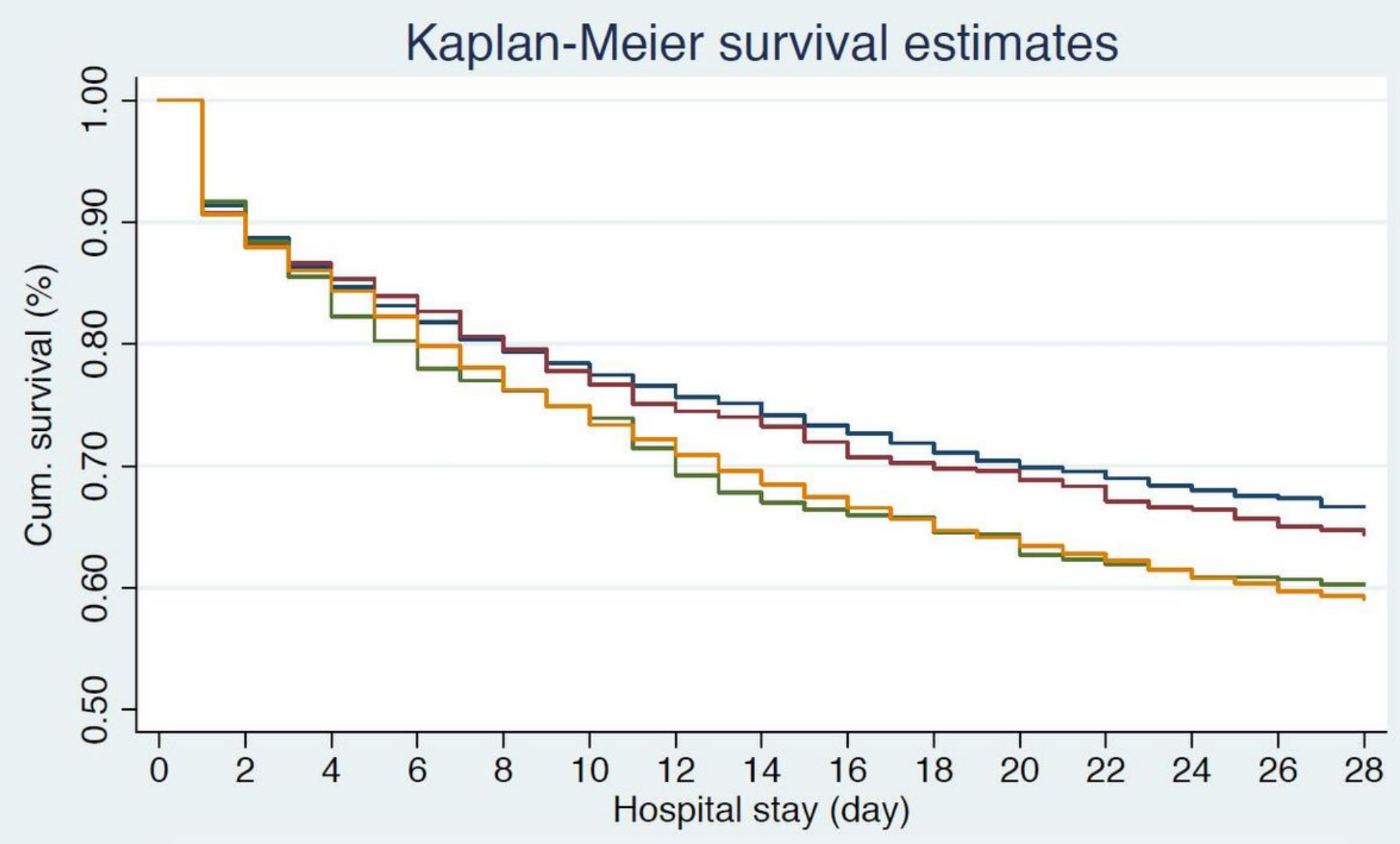

Within $3 \mathrm{hr}$

Between 3 and $6 \mathrm{hr}$

Between 6 and $12 \mathrm{hr}$ Not measured within $12 \mathrm{hr}$

Figure 2

Mortality rate in patients with different Initial central venous pressure The bar plot demonstrates the raw mortality rate in each patient subgroup with different Initial central venous pressure. Locally weighted smoothing (Lowess Smoothing) showed a " $U$ "-shaped relationship between initial central venous pressure and mortality. 


\section{Mortality Rate of Different Initial CVP}

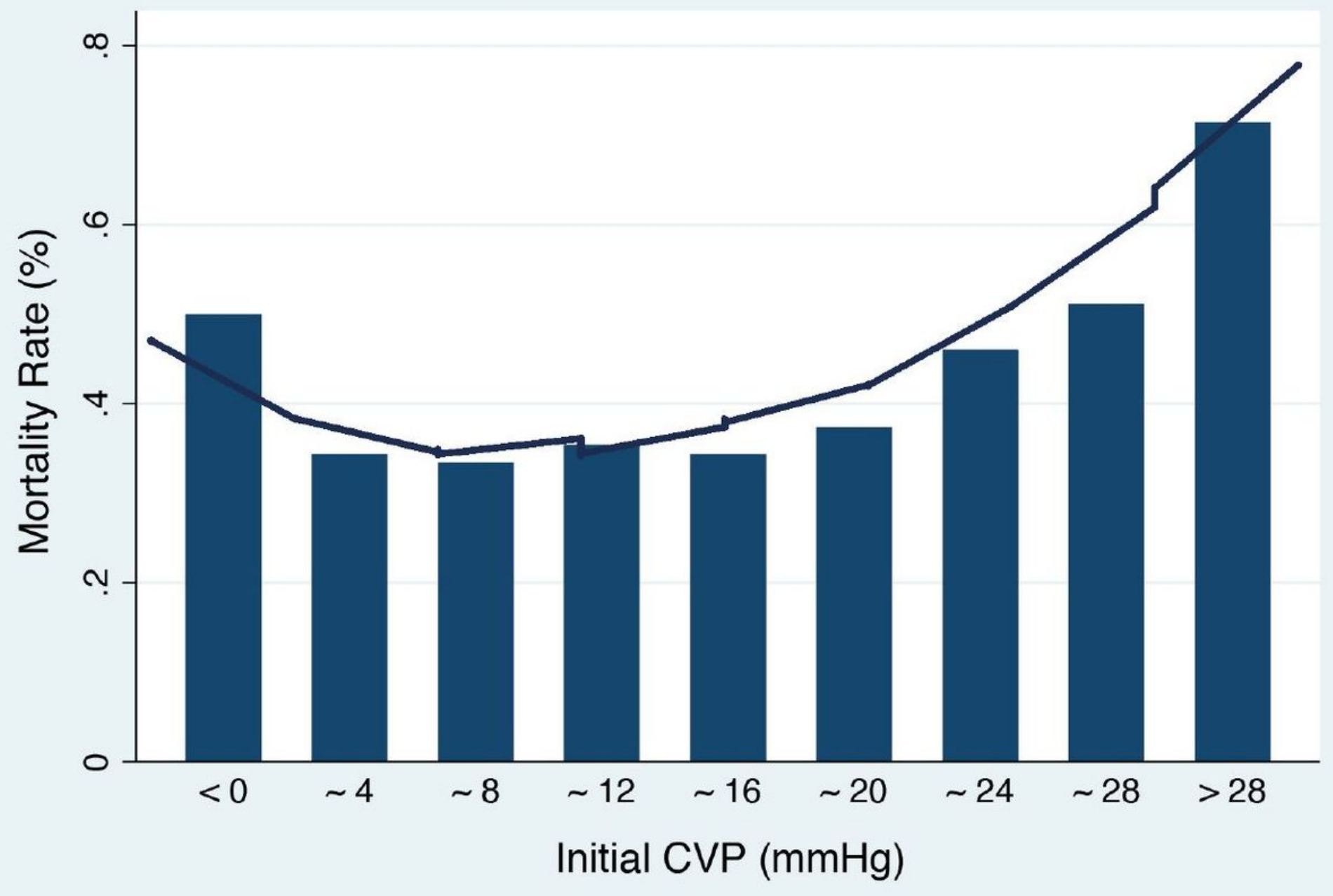

Figure 3

Kaplan-Meier survival analysis of patients with central venous pressure measured at different time points The 28-day survival was significantly different among patients with central venous pressure (CVP) measured at the different time points (CVP measured within 3 hours, between 3 and 6 hours, between 6 and 12 hours, and not measured within 12 hours, $p<0.001$ ). Pairwise comparison showed a significant difference between patients with CVP measured within 3 hours and patients without CVP measured within 12 hours (adjusted $p<0.001$ ). A statistical trend was observed between patients with CVP measured between 3 and 6 hours and patients without CVP measured within 12 hours (adjusted $p=$ 0.053). No difference was observed between patients with CVP measured between 6 and 12 hours and those who without CVP measured within 12 hours (adjusted $p>0.999$ ). 